IZA DP No. 9744

The Entrepreneurship Beveridge Curve

Thomas Gries

Stefan Jungblut

Wim Naudé

February 2016 


\title{
The Entrepreneurship Beveridge Curve
}

\author{
Thomas Gries
}

Paderborn University

Stefan Jungblut

Paderborn University

\author{
Wim Naudé \\ Maastricht University, MSM \\ and IZA
}

\section{Discussion Paper No. 9744 \\ February 2016}

\author{
IZA \\ P.O. Box 7240 \\ 53072 Bonn \\ Germany \\ Phone: +49-228-3894-0 \\ Fax: +49-228-3894-180 \\ E-mail: iza@iza.org
}

Any opinions expressed here are those of the author(s) and not those of IZA. Research published in this series may include views on policy, but the institute itself takes no institutional policy positions. The IZA research network is committed to the IZA Guiding Principles of Research Integrity.

The Institute for the Study of Labor (IZA) in Bonn is a local and virtual international research center and a place of communication between science, politics and business. IZA is an independent nonprofit organization supported by Deutsche Post Foundation. The center is associated with the University of Bonn and offers a stimulating research environment through its international network, workshops and conferences, data service, project support, research visits and doctoral program. IZA engages in (i) original and internationally competitive research in all fields of labor economics, (ii) development of policy concepts, and (iii) dissemination of research results and concepts to the interested public.

IZA Discussion Papers often represent preliminary work and are circulated to encourage discussion. Citation of such a paper should account for its provisional character. A revised version may be available directly from the author. 
IZA Discussion Paper No. 9744

February 2016

\section{ABSTRACT}

\section{The Entrepreneurship Beveridge Curve}

We propose that the rate of creation and failure of start-up firms can be modelled as a search and matching process, following labor market matching models. Setting out an endogenous growth model with entrepreneurship we derive a Entrepreneurship Beveridge Curve, through which we illustrate that entrepreneurial start-ups are the outcome of the efficiency with which entrepreneurial abilities are matched with business opportunities. The Entrepreneurship Beveridge Curve is a potentially useful analytical tool to add to the formalization of the economics of entrepreneurship, and we mention a number of extentions and applications.

JEL Classification: L26, M13, O10, O14

Keywords: entrepreneurship, start-ups, labor market matching

Corresponding author:

Wim Naudé

Maastricht School of Management (MSM)

PO Box 1203

6201 BE Maastricht

The Netherlands

E-mail:w.naude@maastrichtuniversity.nl 


\section{Introduction}

Although there are many definitions of entrepreneurship in most it is about the discovery and exploitation of opportunities (Shane and Venkataraman, 2000). How entrepreneurs spot and exploit opportunities to start-up new firms has spawned a large literature (e.g. Buenstorf, 2007; Casson and Wadeson, 2007; O'Fiet and Patel, 2008, Plummer et al., 2007 and Ucbasaran et al. 2008).

A feature of the start-up process noted in this literature is that while there is a large pool of latent entrepreneurs, many with highly developed human capital, only a small proportion of them succeed in starting up a firm. This has been explained with reference to human capital (e.g. Lazear, 2005) and the nature (and context) of opportunities that prospective entrepreneurs face (e.g. Blanchflower and Oswald, 1998).

In this paper we take these two ideas - the human capital of entrepreneurs and the nature of opportunities - to propose a novel way of understanding startups $^{1}$. Our aim is to make a modest theoretical contribution to the economics of entrepreneurship. In particular, we borrow and adapt the concept of labor market matching from the field of labor economics, and apply it to describe startups as the outcome of a match between entrepreneurs with appropriate ability (human capital) and business opportunities. Obstacles to start-ups, including lack of credit or stifling regulations can then in our theoretical model be analyzed as frictions in the matching of entrepeneurial ability and opportunities.

In this paper we explain our contribution intuitively in section 2.1. In the rest of section 2 we then explain the building blocks of our model. In section 3 we illustrate the model's comparative statics and moreover derivation what we term the Entrepreneurship-Beveridge Curve, our key contribution. Having explained through the Entrepreneurship-Beveridge Curve our idea of start-ups as the result of a matching process we discuss policy recommendations and avanues for further research in section 4 .

\section{The Matching Approach}

\subsection{Intuitive Explanation}

At any given time there will exist a number of opportunities that entrepreneurs may exploit to start-up firms. These opportunities are constantly evolving, and may spur both new firm start-ups as well as firms exits (churn). A useful way to model this situation is through the labor market matching approach. It has been applied to various fields in economics. Representative references for the labor market are Montgomery (1991), Mortensen and Pissarides (1999), Acemoglu and Shimer (2000) and Pissarides (2000).

The matching approach allows us to explain certain empirical features of entrepreneurship such as constantly evolving start-up opportunities, high exit rates, and the development of heterogeneous products (i.e. innovation). A

\footnotetext{
${ }^{1}$ This idea was first proposed in a more rudimentary fashion by Gries and Naudé (2010; 2011). Here we elaborate the idea and propose its more general use in a variety of settings in formalizing the role of the entrepreneur in economic theory.
} 
match between entrepreneurial ability and the requirements of the opportunity (market) will result in a start-up. Since the efficiency of this matching reflects the efficiency of overcoming frictions, such as information and transaction costs, the efficiency of the matching process also reflects the quality of the institutional framework in this market. To model these ideas we introduce a stylized version of the matching approach and apply it to entrepreneurship in the following sub-sections.

\subsection{Entrepreneurs}

We make a distinction between active entrepreneurs, $n$ and latent entrepreneurs $u$. Entrepreneurs are the creators and subsequent owners and managers of the firms in our model. Hence our notion of entrepreneurs corresponds to the definition of entrepreneurship as the "process of starting and continuing to expand new businesses' (Hart, 2003:5). As these firms come into being through the spotting and utilization of opportunities our notion of entrepreneurship is also consistent with Shane and Venkataraman (2000)'s definition of entrepreneurship as being about opportunities. A latent entrepreneur is a person who would prefer to be an entrepreneur and who considers seeking, or is actively seeking, an opportunity (Blanchflower et al. 2001). Around 25 percent of the labor force in OECD countries may be latent entrepreneurs (ibid. p.610). Given entrepreneurs and latent entrepreneurs represent the total entrepreneurial potential in the economy, $E$, and can be written as $E=n+u$.

\subsection{Opportunities}

Latent entrepreneurs search for opportunities to start up a firm. We assume that available opportunities are exogenously given - i.e. opportunities exist independently of entrepreneurs. In fact, we can think of opportunities as a potential or already observable demand for a product variation in the respective market. We denote the total number of potential start-up opportunities by $\Omega$. At any time $t$, there are three types of start-up opportunity. First, there are opportunities that have already bee taken, and is reflected in the active entrepreneurs and their start-ups, $n$. Second, there are a number $\omega$ of unrealized profitable opportunities ready for the exploitation. Third, there are unrealized but idle (or yet unproductive) opportunities available, denoted by $\delta$. These may be "opportunities " in the informal sector that are (currently) not profitable. People are often forced into assuming these opportunities when they cannot obtain wage employment or spot a profitable opportunity. The total number of opportunities for a start-up firm can thus be written as

$$
\Omega=n+\omega+\delta
$$

\subsection{A Start-Up as a Match}

A start-up firm results when the entrepreneur spots and utilizes an opportunity that matches his or her abilities. The number of new start-up firms that result from such a matching is $\mathcal{M}$ in any period. In aggregate this matching rate, 
the start-up rate, will be the result of three factors. The first is the business or investment climate in the country. The investment climate, which reflects the institutional framework of the economy will determine how efficient the matching process is. For instance, an alert entrepreneur may spot a profitable opportunity, but may be prevented for utilizing it (i.e. from being matched to the opportunity). The overall matching efficiency in the economy is denoted $\mu$. The second determinant of the matching (start-up) rate is the extent of unrealized profitable opportunities, denoted by $\omega$. This reflects the fact that latent entrepreneurs are often constrained by a lack of suitable or profitable opportunities. The third determinant of the matching (start-up) rate is the capability of the entrepreneur, which is reflected in how intense he or she may be searching for opportunities. The literature that the keenness and search intensity of latent entrepreneurs varies quite considerably. We denote this search intensity by $\eta$ so tha that $\mathrm{n}$ aggregate the $u$ latent entrepreneurs have search intensity of $\eta u$ which can also be seen as total entrepreneurial capital in a country. As we show in the next section, there are costs involved in searching (or in having a more substantial entrepreneurial capital stock); the greater the search intensity, the higher the cost.

Given these determinants of the matching (start-up) rate we can assume that the matching rate $\mathcal{M}$ can be written as:

$$
\mathcal{M}=\mu M(\omega, \eta u),
$$

where $\eta u$ denotes effective search efforts of entrepreneurs. Throughout the paper, we will assume that the rate of matches per entrepreneur and the rate of matches per opportunity depends on the ratio of opportunities to entrepreneurs only but not on the size of the economy. This results in linear homogeneity of the matching function. In case of increasing or decreasing returns to scale in matching the effectiveness of the matching process would vary according to the size of the economy. Although this might be reasonable to some extent and interesting, we think that this effect whould not be systematic. Rather it will be the result of differences in the institutional quality and investment climate and captured in $\mu$. Further, for computational simplicity we will model the matching-function as a Cobb-Douglas function:

$$
\mathcal{M}=\mu \omega^{\beta}(\eta u)^{1-\beta} .
$$

From this we can show that the probability of a successful firm start-up is $\mu M / u=\mu m$.

\subsection{Optimal Search and Investment Intensity, Matching, and Firm Failure}

On the individual level, the potential entrepreneur $i$ will have to make a search effort with the intensity $\eta_{i}$ in order to spot an opportunity. As we mentioned, such a search is costly. The search cost per unit of search effort is $c_{i}$.

Apart from latent entrepreneurs facing search costs, existing entrepreneurs also face costs, because they will have to invest a certain effort $\psi_{i}$ to ensure their 
firm's survival - for instance through constant product and process innovation. The optimal search intensity to enter the market and the optimal investment or innovation intensity (effort) to stay in the market will be the result of maximizing entrepreneurs' net present value. ${ }^{2}$ We assume that entrepreneurs are identical and all entrepreneurial ventures yield the same expected profit (net of wages). The optimization problem of a representative entrepreneur then needs to include two states: (i) the state of being a wage employed latent entrepreneur searching for opportunities and (ii) the state of being an entrepreneur, and trying to stay in business.

i) For the state of a wage employed latent entrepreneur, the net present value of searching, $W_{i}$, is given by wage income $w_{i}$ minus search costs $c_{i}$ times search intensity $\eta_{i}$ plus the additional entrepreneurial income that can be expected if an opportunity is spotted andexplouted through a start-up firm. With $V_{i}$ as the value of entrepreneurial income then the average additional entrepreneurial income can be written as $\Delta=V-W$. This additional entrepreneurial income is uncertain: $\Delta$ is weighted by the probability of matching. In the previous subsection we established that the probability of matching is $\mu m_{i}$. Since individual efforts affect the matching probability $m_{i}\left(\eta_{i}\right)$ for a given discount rate $r$ we obtain

$$
r W_{i}=w_{i}-c_{i} \eta_{i}+\mu m_{i}\left(\eta_{i}\right) \Delta
$$

ii) For the state of an existing entrepreneur actively working to keep the firm going, the net present value of being an active entrepreneur $V_{i}$ is

$$
r V_{i}=v_{i}-\gamma_{i} \psi_{i}-\phi_{i}\left(\psi_{i}\right) \Delta
$$

The profits are $v_{i}$. In order for his or her firm to survive the entrepreneur would need to invest $\gamma_{i} \psi_{i}$ with effort $\psi_{i}$. These required investments (perhaps in innovation) reflect the transitory and dynamic nature of markets. Despite such investments, a firm failure can still occur. We denote the rate of firm failure by $\phi_{i}$. From the perspective of the individual entrepreneur $i$, their investment efforts $\psi_{i}$ may reduce the likelihood of firm failure $\phi_{i}$ which follows $\phi_{i}=\phi_{i}\left(\psi_{i}\right)$, $\phi_{\psi_{i}}:=\frac{\partial \phi_{i}}{\partial \psi_{i}}<0, \phi_{\psi_{i} \psi_{i}}:=\frac{\partial^{2} \phi_{i}}{\partial \psi_{i}^{2}}>0$

The above implies that the entrepreneur has the choice to extend personal effort to enhance the probability of finding a match and to lower the probability of firm failure. They can maximize the expected income in both states of occupation, being a wage employed latent entrepreneur but searching for an opportunity, or being an active entrepreneur trying to stay in business. Thus the optimal search intensity, and the optimal effort to make the investments in a current firm most effective will be a result of the following maximization:

$$
\begin{gathered}
\max _{\eta_{i}}: \quad r W_{i}=w_{i}-c_{i} \eta_{i}+\mu m_{i}\left(\eta_{i}\right) \Delta \\
\max _{\psi_{i}}: \quad r V_{i}=v_{i}-\gamma_{i} \psi_{i}-\phi_{i}\left(\psi_{i}\right) \Delta
\end{gathered}
$$

\footnotetext{
${ }^{2}$ We can also introduce unemployed persons searching for opportunities while still on welfare benefits, but for the sake of tractability we abstract from this possibility.
} 
From the F.O.C. we obtain an optimal search effort $\eta^{*}$ and optimal investment effort $\psi^{*}$ by using the implicit function theorem ${ }^{3}$

$$
\begin{gathered}
\eta^{*}=\eta^{*}\left(u, \omega, \Delta_{i}, c_{i}, \mu\right), \quad \text { with } \quad \begin{array}{l}
\eta_{u}<0, \quad \eta_{\omega}>0, \quad \eta_{\Delta}>0, \\
\eta_{c_{i}}<0, \quad \eta_{\mu}>0
\end{array} \\
\psi^{*}=\psi^{*}\left(\Delta, \gamma_{i}\right), \quad \text { with } \quad \begin{array}{l}
\psi_{\gamma_{i}}<0, \quad \psi_{\Delta}>0
\end{array}
\end{gathered}
$$

\subsection{Aggregate Equilibrium Outcome}

Assuming identical behavior across entrepreneurs we now consider the implications for the economy's aggregate equilibrium outcome.

First, we derive the representative wealth differential $\Delta$ of the two wealth levels $(W$ and $V)$ associated with being a latent entrepreneur or with being an active entrepreneur. From the vector $x=(u, \omega, \Delta, c, \mu)$ we can derive the implicit relation for the wealth differential between occupations:

$$
\Delta=\frac{v-w+c \eta(x)-\gamma \psi(\Delta, \gamma)}{r+\phi(\psi(\Delta, \gamma))+\mu m(\eta(x))}
$$

This equation determines the wealth differential $\Delta$ as the present value of the net income difference of the two occupational states. The discount factor equals the interest rate $r$ plus transition probabilities.

Second, we derive an expression to express churning of firms in the economy, i.e. the differences in start-ups and failures. In a long-run stationary equilibrium the number of new firm start-ups will equal the number of firm failures. Given the probability of firm failure as noted in the previous subsection the number of firm failures on the aggregate level is denoted as $\phi n$. The failure rate $\phi$ covers all causes for firm failure including the possibility that a so far profitable and taken opportunity suddenly might turn idle leading to the bankruptcy of the business. ${ }^{4}$ The number of new firm start-ups is equal to $\mu M$. Hence the churning rate of firms in our economy is $\dot{n}=\mu M-\phi n$. The associated stationary flow equilibrium condition is:

$$
\dot{n}=0 \quad \Leftrightarrow \quad \mu M=\phi n
$$

Third, in order to determine the aggregate equilibrium number of startups we need to consider the dynamics of opportunities in the economy. We suppose that these dynamics are captured by two probabilities namely $p$ and $q$. Here $p$ is the probability that profitable opportunities become unprofitable, while $q$ is the probability of formerly idle opportunities will become profitable. ${ }^{5}$ These probabilities may be determined by exogenous changes such as structural change, shifts in demand or tastes, the rate and nature of economic growth,

\footnotetext{
${ }^{3}$ See appendix 1 .

${ }^{4}$ Fur further explanation see also footnote 5

${ }^{5}$ Note that $p n$ does not explicitly enter equation (2). As $\phi n$ is the total number of firm failures due to all causes, $p n$ is an independent subset of $\phi n$. Hence, the set of total failures $\phi n$ already includes failures due to the fact that a so far profitable business ( taken opportunity) suddenly becomes unprofitable, $p n$.
} 
political instability, and rates of technological progress. Thus the dynamics (rate of change) in idle start-up opportunities is $\dot{\delta}=p(\omega+n)-q \delta$. The associated stationary flow equilibrium for opportunities is ${ }^{6}$

$$
\dot{\delta}=0 \quad \Leftrightarrow \quad \omega=\frac{q}{p+q} \Omega-E+u
$$

With equation (1), (2) and (3) we have a system of three equations with three endogenous variables $(u, \omega, \Delta)$. The system is determined by information, transactions costs, institutional features and general business environment. These depend on the general matching efficiency $\mu$, transaction costs $c$ in the start-up phase, and the adjustment costs $\gamma$ for firm survival. Furthermore, the general business environment is reflected in market demand and the ability of markets to absorb new product variations $\Omega$ and the total entrepreneurial potential of the economy $E$.

$0=F=\phi\left(\psi^{*}\right)(E-u)-\mu M\left(\omega, u, \eta^{*}\right) \quad$ stationary matching equilibrium

$0=G=\Delta\left(r+\phi\left(\psi^{*}\right)+\mu M\left(\omega, u, \eta^{*}\right) / u\right)-v+\gamma \psi^{*}+w-c \eta^{*} \quad$ wealth diff.

$0=H=\omega-\frac{q}{p+q} \Omega+E-u \quad$ supply of profitable opportunities

From the system of equations we can derive Proposition 1.

Proposition 1 The economy [the system of equations $F, G, H$ ] has a stationary matching equilibrium solution of firm creation and firm failure, and hence a stationary number of latent entrepreneurs $u^{*}$, unrealized but profitable opportunities $\omega^{*}$ and a stationary differential of entrepreneurial and labor wealth $\Delta^{*}$, as long as $\frac{q}{p+q} \Omega-E>0 \rightarrow \omega>u$.

$$
u^{*}=u^{*}(x), \quad \omega^{*}=\omega^{*}(x), \quad \Delta^{*}=\Delta^{*}(x)
$$

where $x=(\mu, c, \gamma, p, q, \Omega, E, v, w)$. For a proof, see Appendix 2 .

Proposition 1 implies that there will be a constant number of firms in the economy. With a stationary number of firms we can identify the extent to which the entrepreneurial potential in the economy can be realized. We can also determine how the stationary wealth premium $\Delta^{*}$ for a representative entrepreneur. This will be a meaure of how efficient the economy is towards entrepreneurship. In an ideal market economy without frictions all opportunities will be utilized and there is no need for anyone else to become an entrepreneur. Therefore, we describe the market as a location (or institutional framework) which may or may not be fulfilling its purpose efficiently.

\footnotetext{
${ }^{6}$ We use the definition $\Omega=n+\omega+\delta$ to substitute for $\delta$.
} 


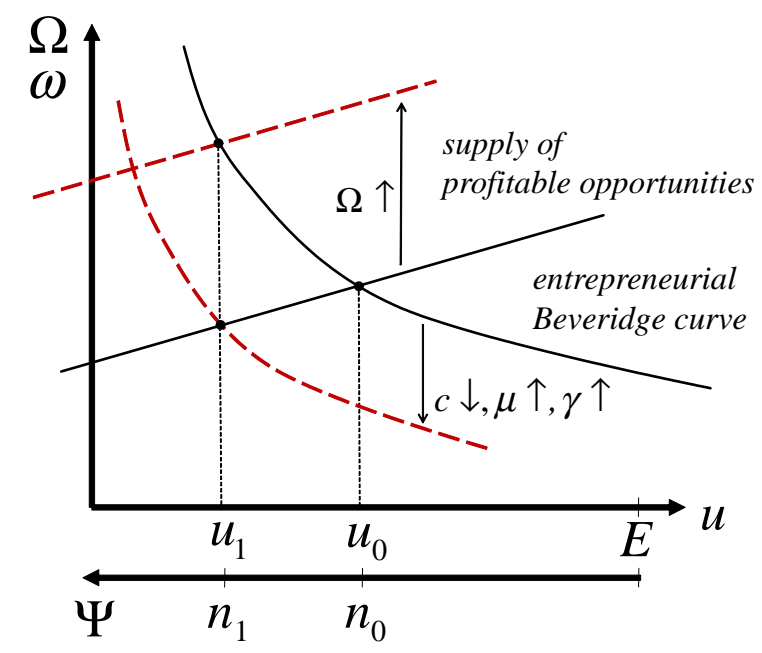

Figure 1: The Entrepreneurship Beveridge Curve

\section{The Entrepreneurship Beveridge Curve and Implications}

The key contribution of our paper is to explain firm creation and failure as the outcome of a matching process. Because matching models have been frequently applied in labor economics we can draw on this tradition to illustrate our approach. A useful instrument in this tradition is the Beveridge Curve. In labor economics the Beveridge Curve, proposed by Dow and Dicks-Mireaux (1958), depicts the relationship between job vacancy rates and the unemployment rate, and measures labor market efficiency to the extent to which it allows matching between labourers and job vacancies. As we extend these notions to the case of entrepreneurs searching for opportunities, we can derive an Entrepreneurship Beveridge Curve in Proposition 2.

Proposition 2 From equation (1) and (2) we implicitly obtain a function describing all potential matching equilibria. We call this locus of potential matching equilibrium the Entrepreneurship Beveridge Curve. As long as $1>\frac{\phi_{\psi}}{\phi} \frac{\phi_{\psi}}{\phi_{\psi \psi}}$ we obtain for this curve $\omega=B(u, x)$, with

$$
\frac{d \omega}{d u \mid B}_{\mid B}<0, \frac{d \omega}{d c \mid B}_{\mid B}>0, \quad{\frac{d \omega}{d \mu_{\mid B}}}_{1}<0, \text { and }{\frac{d \omega}{d \gamma_{\mid B}}}_{<0}
$$

where $x=(\mu, c, \gamma, p, q, \Omega, E, v, w)$. For a proof see Appendix 2 .

The Entrepreneurship Beveridge Curve describes the equilibrium relation between unrealized profitable opportunities and latent entrepreneurship. Hence, this relation indicates how frictionless or not the economy is. The curve is an instrument to identify the institutional efficiency and the severeness of market 
frictions with respect of information and transaction costs. For instance, an Entrepreneurship Beveridge Curve located in the north-west of the figure indicates high inefficiency. This may be due to strong frictions in information and transaction efficiency, ineffective institutions, excessive regulations, and/or diverging interests between customers and potential entrepreneurs. The slope of the eEntrepreneurship Beveridge Curve describes how for given market conditions decreasing business opportunities drive down the number of firms in the market $n$ and/or drive up the number of latent entrepreneurs $u$ in the economy.

The second curve in Figure 1 is the supply curve of profitable opportunities. This curve describes the relationship between latent entrepreneurs and the supply of profitable opportunities for the given in- and outflow connected with the idle (or yet unproductive) opportunities $\delta$. Equilibrium in the market occurs where the Entrepreneurship Beveridge Curve intersects the supply curve of profitable opportunities.

While Figure 1 enables us to graphically illustrate the matching equilibrium and comparative static adjustments, we can also graphically illustrate how changes in the market matching process affect important economic indicators like the mobilization rate of entrepreneurial potential. For this purpose we can draw a second axis starting at the given number of potential entrepreneurs $E$. This axis points to the opposite direction than the $u$-axis because it counts the number of active entrepreneurs. For a given $E$ this axis hence also indicates the mobilization rate of the entrepreneurial potential of this economy. The Entrepreneurship Mobilization Rate is an important indicator as it describes the extend to which an economy is able to mobilize the entrepreneurial capacity. Entrepreneurs have an important function in a market economy and hence are an important resource. If an economy is unable to bring the latent entrepreneurs to the market it will not fully use this source of wealth. In this model we define Entrepreneurship Mobilization Rate as the percentage rate of existing firms in relation to the total entrepreneurial potential in the economy $\Psi=\frac{n}{E}$.

While we leave further elaborations and the application of the model to future modelling, we wish to illustrate how the comparative statics of the model can reveal the determinants of firm creation and failure and can generate policy recommendations. In particular we are interested in the start-up rate as the percentage rate of new firms in relation to existing firms $\varepsilon=\frac{\mathcal{M}}{n}$, the survival rate as the percentage rate of successful surviving firms in relation to existing firms $\lambda$, and the total mobilization of an economy's entrepreneurial potential $\Psi=\frac{n}{E}$. For these indicators we determine the effects of (i) the general market environment and the institutional quality indicated by the matching efficiency parameter $\mu$, (ii) information and transaction costs during the start-up phase $c$, and (iii) investment costs to maintain the firm in the market $\gamma$. Finally we show that a growing economy promotes start-ups and firm survival, and generally improves the mobilization of an economy's entrepreneurial potential. While Figure 1 provides a graphical illustration we also derive the resulting effects in Propositions 3, 4 and 5 in order to complete the analysis and formally proofs.

Proposition 3 An improved matching efficiency, $d \mu>0$, will (i) increase the matching and start-up rate in the economy $\varepsilon=\frac{\mathcal{M}}{n}$, (ii) improve the total 
mobilization of an economy's entrepreneurial potential $\Psi=\frac{n}{E}$, and (iii) decrease the rate of firm survival $\lambda=1-\phi$, as long as $\frac{q}{p+q} \Omega-E>0 \rightarrow$ $\omega>u$ (i.e. number of profitable opportunities is larger than number of latent entrepreneurs):

$$
\frac{d \varepsilon}{d \mu}>0, \quad \frac{d \Psi}{d \mu}>0, \quad \frac{d \lambda}{d \mu}<0 .
$$

For a proof, see Appendix 3.

The above proposition makes intuitively sense. However, the effect $\frac{d \lambda}{d \mu}<0$ may require a short explanation. An increasing matching efficiency in the start-up phase increases the profitability of start-up efforts. Therefore, greater proportional effort is invested in this activity so that the start-up rate increases and the survival rate decreases.

Proposition 4 Higher information and transaction costs during start-up dc > 0 , will (i) reduce the matching and the start-up rate $\varepsilon$, (ii) reduce the total mobilization of an economy's entrepreneurial potential $\Psi$, and increase efforts required for firm survival $\lambda$. As long as $\frac{q}{p+q} \Omega-E>0 \rightarrow \omega>u$.

$$
\frac{d \varepsilon}{d c}<0, \quad \frac{d \Psi}{d c}<0, \quad \frac{d \lambda}{d c}>0 .
$$

Further, higher investment costs to ensure firm survival, i.e. $d \gamma>0$, will (i) stimulate efforts to start up a new firm and raise the start-up rate $\varepsilon$, (ii) reduce the total mobilization of an economy's entrepreneurial potential $\Psi$, and (iii) depress the rate of firm survival $\lambda$,

$$
\frac{d \varepsilon}{d \gamma}>0, \quad \frac{d \Psi}{d \gamma}<0, \quad \frac{d \lambda}{d \gamma}<0
$$

For a proof see Appendix 3.

While most of the effects described in the proposition are intuitively clear the cross-effects of the two kinds of cost require some explanation. If the transaction costs of starting a new firm increase $(d c>0)$ it will be relatively more attractive to stay in business, hence the relative effort to ensure survival increases and the survival rate rises. Symmetrically, if investment costs for keeping the firm in business increase $(d \gamma>0)$ it becomes relatively more attractive to try something new rather than keeping the existing firm going. Hence less efforts are invested in firm survival since new opportunities can be pursued. As a result the survival rate decreases and the start-up rate rises. This is counter-intuitive and caution against the common wisdowm that the same factors that contribute to firm failure will constrain new start-up activities.

Finally we consider the effects of economic growth. In Figure 1 we plot an upward shift in the supply curve of opportunities. With economic growth and an increase in aggregate demand the number of opportunities increase and following proposition 5 this improves market efficiency. 
Proposition 5 An economic expansion that increase the number of opportunities $\Omega$ for new business will (i) increase the matching and the start-up rate $\varepsilon$, (ii) improve the total mobilization of an economy's entrepreneurial potential $\Psi$, and (iii) decrease firm survival $\lambda$, as long as $0<1-\frac{(-)}{\phi} \frac{\phi_{\psi}}{\phi_{\psi} \psi}:^{7}$

$$
\frac{d \varepsilon}{d \Omega}>0, \quad \frac{d \Psi}{d \Omega}>0, \quad \frac{d \lambda}{d \Omega}<0
$$

For a proof see Appendix 3.

It is not only an exogenosu economic expansion that may improve opportunities. Deliberate trade policy, e.g. a reduction in trade barriers, may for instance also improve opportunities. Such further applications of our model is left for future examination.

\section{Concluding Remarks}

In this paper we offered a novel way to formally model entrepreneurship in an endogenous growth model setting. We did this by explaining start-ups as the result of a match between entrepreneurs and opportunities. In this matching and the subsequent survival of firms entrepreneurial ability, search intensity, and investment efforts are crucial parameters. However, even when individual entrepreneurs raise the intensity with which they search for opportunities and increase their investment and innoavtion efforts in existing firm, firm start-up and failure rates will still be affected by the overall investment climate (and hence the institutional framework) in the economy. Even though some entrepreneurs may overcome adverse conditions for doing business, many others will not, and the aggregate mobilization of entrepreneurial capacity in the economy will be reduced.

The comparative statics of our model allowed us to show how transaction costs and the investment climate will affect the matching (start-up) rate and the rate of firm failure. Some of the policy implications that we derived from this includes that measures to increase the aggregate mobilization of entrepreneurial capacity in the economy need to address both the individual entrepreneur, and not just the aggregate business environment. Business environment reform which is at the core of most private sector development programmes is not sufficient.

If the creation and survival of new firm start-ups are an essential ingredient of economic development then our approach offers a useful insight into the process underlying this churning of firms. An advantage of our approach is that it treats

\footnotetext{
${ }^{7}$ This condition is a sufficient condition and states that the external market environment must have a sufficiently strong effect on the probability of staying in business. That is, even if an entrepreneur puts more effort into staying in the market, this additional effort has limited effects and will not strongly improve the chances of survival. This condition is also sufficient to ensure the negative slope and normal reactions of the entrepreneurial Beveridge curve in figure 1 .
} 
both the creation and the failure of new start-ups as the result of a mismatch between opportunities and entrepreneurs - including their ability and external environment.

The model has the potential to be extended to include linkages between search intensity and the degree to which entrepreneurship is valued in itself, as opposed to merely being an instrument to achieve other outcomes. Future applications could furthermore explore institutional entrepreneurship, that is to say, how individual search efforts could contribute to a better (or worse) business environment as well explore how innovation policy can improve the matching entrepreneurs to specific opportunities, and how investors can be matched with venture capitalists. We believe that these are just a few of the potential areas where labor economics' idea of matching can be applied to the formalization of entrepreneurship in economic theory.

\section{References}

[1] Acemoglu, Daron. and Shimer, Robert. 2000. 'Wage and Technology Dispersion', Review of Economic Studies, 67.4, pp. 585-607.

[2] Blanchflower, David G., Oswald, Andrew J. and Stutzer, Alois. 2001. 'Latent Entrepreneurship Across Nations', European Economic Review, 45: 680-91

[3] Blanchflower, David G. and Oswald, Andrew J. 1998. 'What Makes an Entrepreneur?' Journal of Labor Economics, 16 (1): 26-60.

[4] Buenstorf, Guido. 2007. 'Creation and Pursuit of Entrepreneurial Opportunities: An Evolutionary Economics Perspective', Small Business Economics, 28 (4): 323-358.

[5] Casson, Mark and Wadeson, Nigel. 2007. 'The Discovery of Opportunities: Extending the Economic Theory of the Entrepreneur', Small Business Economics, 28 (4): 285-301.

[6] Dow, J. C. R. and Dicks-Mireaux, L. 1958. 'The Excess Demand for Labour: A Study of Conditions in Great Britain, 1946-1956', Oxford Economic Papers, 10 (1): 1-33.

[7] Gries, Thomas and Naudé, Wim. 2010.'Entrepreneurship and Structural Economic Transformation', Small Business Economics, 34 (1): 13-29.

[8] Gries, Thomas and Naudé, Wim. 2011. 'Entrepreneurship and Human Development: A Capabilities Approach', Journal of Public Economics, 95 (3): 216-224.

[9] Lazear, Edward P. 2005. 'Entrepreneurship', Journal of Labor Economics, 23 (4): 649-680. 
[10] Hart, David M. 2003. 'Entrepreneurship Policy: What it is and Where it came from', in Hart, D.M. (ed.) The Emergence of Entrepreneurship Policy: Governance, Start-ups and Growth in the U.S. Knowledge Economy. Cambridge: Cambridge University Press: 3-19.

[11] Montgomery, James D. 1991. 'Equilibrium Wage Dispersion Interindustry Wage Differentials', Quarterly Journal of Economics. 106 pp. 163-79.

[12] Mortensen, Dale T. and Pissarides, Christopher A. 1999. 'Job Reallocation, Employment Fluctuations, and Unemployment', Handbook of Macroeconomics Michael Woodford and John B. Taylor, eds. Amsterdam NorthHolland, pp.1171-228.

[13] O'Fiet, James and Patel, Pankaj C. 2008. 'Entrepreneurial Discovery as Constrained, Systematic Search'. Small Business Economics, 30 (3): 215229 .

[14] Pissarides, Christopher A. 2000. Equilibrium Unemployment Theory. 2nd ed. Oxford: Basil Blackwell.

[15] Plummer, Lawrence A., Haynie, J.M. and Godesiabois, Joy. 2007. 'An Essay on the Origins of Entrepreneurial Opportunity', Small Business Economics, 28 (4). 363-380.

[16] Shane, Scott and Venkataraman, Sankaran. 2000.'The promise of entrepreneurship as a field of research', The Academy of Management Review, 25: $217-226$.

[17] Ucbasaran, David, Westhead, Paul and Wright, Mike. 2008. 'Opportunity Identification and Pursuit: Does an Entrepreneur's Human Capital Matter?', Small Business Economics, 30 (2): 153-174.

\section{Appendices}

\subsection{Appendix 1: Determining Optimal Effort Levels}

Search effort: Determining the optimal search effort, the effort function $\eta$ and derivatives:

$$
\max _{\eta_{i}}: r W_{i}=w_{i}-c_{i} \eta_{i}+\mu \frac{\omega^{\beta}\left(\eta_{i} u\right)^{1-\beta}}{u} \Delta
$$

F.O.C. and S.O.C.:

$$
0=-c_{i}+\mu \frac{\Delta}{u}(1-\beta) \frac{M}{\eta_{i}}, \quad 0>-\mu \frac{\Delta}{u}(1-\beta) \beta \omega^{\beta} \eta_{i}^{-\beta-1} u^{1-\beta}
$$

Optimal search effort of each entrepreneur is determined by using the implicit function theorem from the F.O.C. and S.O.C. We obtain

$$
\eta^{*}=\eta^{*}\left(u, \omega, \Delta, c_{i}, \mu\right), \quad \eta_{\Delta}>0, \quad \eta_{\omega}>0, \quad \eta_{u}<0, \quad \eta_{c_{i}}<0, \quad \eta_{\mu}>0
$$


Derivatives of the optimal effort:

$$
\begin{aligned}
& \eta_{\Delta}=\frac{\eta_{i}}{\Delta \beta}>0, \quad \eta_{\omega}=\frac{\eta_{i}}{\omega}>0, \quad \eta_{u}=-\frac{\eta_{i}}{u}<0, \\
& \eta_{c_{i}}=\frac{-1}{\mu \frac{\Delta}{u}(1-\beta) \beta \frac{M}{\eta_{i}^{2}}}<0, \quad \eta_{\mu}=\frac{\eta_{i}}{\mu \beta}>0
\end{aligned}
$$

Stay in market effort: Determining optimal effort to stay in the market, effort function $\psi_{i}$ and derivatives:

$$
\max _{\psi_{i}}: r V_{i}=v_{i}-\gamma_{i} \psi_{i}-\phi_{i}\left(\psi_{i}\right) \Delta
$$

F.O.C. and S.O.C.

$$
-\gamma_{i}-\phi_{\psi_{i}} \Delta=0, \quad-\phi_{\psi_{i} \psi_{i}} \Delta<0
$$

where $\phi_{\psi_{i}}:=\partial \phi_{i} / \partial \psi_{i}$. From the f.o.c. and s.o.c. we obtain the optimal strategy

$$
\psi^{*}=\psi^{*}\left(\Delta, \gamma_{i}\right)
$$

with

$$
\frac{\partial \psi_{i}}{\partial \gamma_{i}}=: \psi_{\gamma_{i}}=-\frac{1}{\phi_{\psi_{i} \psi_{i}} \Delta}<0, \quad \frac{\partial \psi_{i}}{\partial \Delta}=: \psi_{\Delta}=-\frac{\phi_{\psi_{i}}}{\phi_{\psi_{i} \psi_{i}} \Delta}>0
$$

\subsection{Appendix 2: Proof of Proposition 1 and 2}

\subsubsection{Proof of proposition 1}

Equations $F, G, H[(1),(2),(3)]$ have continuous partial derivatives with respect

to all variables. As all variables are positive, and we assume $1>\frac{\phi_{\psi}}{\phi} \frac{\phi_{\psi_{i}}}{\phi_{\psi_{i} \psi_{i}}}$, and since $\frac{q}{p+q} \Omega-E>0 \rightarrow \omega>u$, the determinant of the Jacobian matrix for the smooth function $f(x, y)=(F, G, H)(x, y), y=(\omega, u, \Delta), x=(\mu, c, q, p, \Omega, E, w)$ does not vanish:

$$
\begin{gathered}
A=\left(\begin{array}{ccc}
-\mu \frac{M}{\omega} & -\phi & \bar{\phi}_{\psi} \psi_{\Delta}(E-u)-\mu(1-\beta) \frac{M}{\Delta \beta} \\
\Delta \mu \beta \frac{m}{\omega} & -\Delta \mu \beta \frac{m}{u} & (r+\phi+\mu m) \\
1 & -1 & 0
\end{array}\right) \\
|A|=-(r+\phi+\mu m)\left(\phi+\mu \frac{M}{\omega}\right)+\mu\left(\bar{\phi}_{\psi} \psi_{\Delta}^{+}(E-u) \Delta \beta-\mu(1-\beta) M\right) \underbrace{\left(\frac{m}{u}-\frac{m}{\omega}\right.}_{>0}) \neq 0
\end{gathered}
$$

So that the Jacobian matrix is invertible and the implicit function theorem can be applied. System [(1), (2), (3)] implicitly defines the functions

$$
\begin{aligned}
u^{*} & =u^{*}(\mu, c, v, q, p, \Omega, E, v, w) \\
\omega^{*} & =\omega^{*}(\mu, c, v, q, p, \Omega, E, v, w) \\
\Delta^{*} & =\Delta^{*}(\mu, c, v, q, p, \Omega, E, v, w) .
\end{aligned}
$$




\subsubsection{Proof of Proposition 2 (Entrepreneurship Beveridge Curve):}

Deriving the Entrepreneurship Beveridge Curve: From the first two rows of this system we obtain the entrepreneurial start-up Beveridge curve. The start-up Beveridge curve is in analogy to the labor market Beveridge curve which is derived by taking the first two rows of the system namely equations $F$ and $G$. Equations $F$ and $G[(1),(2)]$ have continuous partial derivatives with respect to all variables. As all variables are positive, and we assume $1>\frac{\phi_{\psi}}{\phi} \frac{\phi_{\psi_{i}}}{\phi_{\psi_{i} \psi_{i}}}$, and since $\frac{q}{p+q} \Omega-E>0 \rightarrow \omega>u$, the determinant of the Jacobian matrix for the smooth function $f(x, y)=(F, G)(x, y), y=(\omega, \Delta), x=(u, \mu, c, q, p, \Omega, E, w)$ does not vanish:

$$
\begin{gathered}
\mathcal{A}=\left(\begin{array}{cc}
-\mu \frac{M}{\omega} & \phi_{\psi} \psi_{\Delta}(E-u)-\mu(1-\beta) \frac{M}{\Delta \beta} \\
\Delta \mu \beta \frac{m}{\omega} & (r+\phi+\mu m)
\end{array}\right) \\
|\mathcal{A}|=-\left[(r+\phi)+\left(-\frac{\phi_{\psi}}{\phi} \frac{\phi_{\psi_{i}}}{\phi_{\psi_{i} \psi_{i}}}+1\right) \frac{\beta \mu M}{u}\right] \mu \frac{M}{\omega} \neq 0
\end{gathered}
$$

So that the Jacobian matrix is invertible and the implicit function theorem can be applied. System [(1), (2)] implicitly defines the function for the Entrepreneurial Beveridge Curve, namely

$$
\omega=B(u, \mu, c, v, q, p, \Omega, E, v, w)
$$

To determine derivatives we can rewrite the above system $\mathcal{A} d \mathrm{a}=d \mathcal{B}$ and determine all derivatives of interest:

$$
\begin{aligned}
\mathcal{A} & =\left(\begin{array}{cc}
-\mu \frac{M}{\omega} & \bar{\phi}_{\psi} \psi_{\Delta}^{+}(E-u)-\mu(1-\beta) \frac{M}{\Delta \beta} \\
\Delta \mu \beta \frac{m}{\omega} & (r+\phi+\mu m)
\end{array}\right) \\
d \mathrm{a} & =(d \omega, d \Delta)^{\prime} \\
d \mathcal{B} & =\left(\begin{array}{c}
\phi d u+\frac{M}{\beta} d \mu-\frac{\eta u}{\Delta \beta} d c-(E-u) \phi_{\psi} \psi_{\gamma} d \gamma \\
-\Delta \mu \beta \frac{m}{u} d u
\end{array}\right)
\end{aligned}
$$

Slope of the Beveridge curve: $\frac{d \omega}{d u}$ From implicit differentiation we obtain

$$
\begin{gathered}
\frac{d \omega}{d u}=\frac{-\left[(r+\phi+\mu m) \phi-\left((E-u) \phi_{\psi} \psi_{\Delta}-\mu(1-\beta) \frac{M}{\Delta \beta}\right) \Delta \mu \beta \frac{m}{u}\right]}{\left[(r+\phi+\mu m) \mu \frac{M}{\omega}+\left((E-u) \phi_{\psi} \psi_{\Delta}-\mu(1-\beta) \frac{M}{\Delta \beta}\right) \Delta \mu \beta \frac{m}{\omega}\right]} \\
\frac{d \omega}{d u}=\frac{-\left[(r+\phi+\mu m) \phi-\left((E-u) \phi_{\psi} \psi_{\Delta}-\mu(1-\beta) \frac{M}{\Delta \beta}\right) \Delta \mu \beta \frac{m}{u}\right]}{\left[(r+\phi)+\left(1-\frac{\phi_{\psi}}{\phi} \frac{\phi_{\psi_{i}}}{\phi_{\psi_{i} \psi_{i}}}\right) \mu m \beta\right] \frac{\mu m u}{\omega}}<0
\end{gathered}
$$

for $\quad 0<1-\frac{\phi_{\psi}}{\phi} \frac{\phi_{\psi_{i}}}{\phi_{\psi_{i} \psi_{i}}} \quad$ as sufficient condition. 
using $\phi_{\psi_{i}}:=\frac{\partial \phi_{i}}{\partial \psi_{i}}<0, \phi_{\psi_{i} \psi_{i}}:=\frac{\partial^{2} \phi_{i}}{\partial \psi_{i}^{2}}>0, \psi_{\Delta}=-\frac{\phi_{\psi_{i}}}{\phi_{\psi_{i} \psi_{i}} \Delta}>0$ and $\mu M=\phi n$, and $\frac{\mu M}{u}=\mu m$

Location of the Beveridge curve: $\frac{d \omega}{d \gamma}, \frac{d \omega}{d \mu}, \frac{d \omega}{d c}:$ Assuming $0<1-\frac{\phi_{\psi}}{\phi} \frac{\phi_{\psi_{i}}}{\phi_{\psi_{i} \psi_{i}}}$ and applying for stationarity $\mu M=\phi n$ gives

$$
\begin{gathered}
\frac{d \omega}{d c}=\frac{(r+\phi+\mu m) \frac{u \eta}{\Delta \beta}}{\left[(r+\phi)+\left(1-\frac{\phi_{\psi}}{\phi} \frac{\phi_{\psi_{i}}}{\phi_{\psi_{i} \psi_{i}}}\right) \mu m \beta\right] \frac{\mu m u}{\omega}}>0 \\
\frac{d \omega}{d \mu}=\frac{\frac{M}{\beta}(r+\phi+\mu m)}{-\left[(r+\phi)+\left(1-\frac{\phi_{\psi}}{\phi} \frac{\phi_{\psi_{i}}}{\phi_{\psi_{i} \psi_{i}}}\right) \mu m \beta\right] \frac{\mu m u}{\omega}}<0 \\
\frac{d \omega}{d \gamma}=\frac{(r+\phi+\mu m)(E-u) \phi_{\psi} \psi_{\gamma}}{\left[(r+\phi)+\left(1-\frac{\phi_{\psi}}{\phi} \frac{\phi_{\psi_{i}}}{\phi_{\psi_{i} \psi_{i}}}\right) \mu m \beta\right] \frac{\mu m u}{\omega}}<0
\end{gathered}
$$

Profitable opportunities curve Taking the implicit differentials for $H$ we obtain

$$
\frac{d \omega}{d u}=1, \quad \frac{d \omega}{d \Omega}=\frac{q}{p+q}
$$

\subsubsection{Appendix 3: Proof of Propositions 3, 4 and 5}

Comparative statics for the system $F, G, H$ can be performed by taking the partial reaction from $A d a=d B$, with

$$
\begin{aligned}
& d a=(d \omega, d u, d \Delta)^{\prime}, \\
& A=\left(\begin{array}{ccc}
-\mu \frac{M}{\omega} & -\phi & \bar{\phi}_{\psi}+\psi_{\Delta}^{+}(E-u)-\mu(1-\beta) \frac{M}{\Delta \beta} \\
\Delta \mu \beta \frac{m}{\omega} & -\Delta \mu \beta \frac{m}{u} & (r+\phi+\mu m) \\
1 & -1 & 0
\end{array}\right) \\
& d B=\left(\begin{array}{c}
\frac{M}{\beta} d \mu-\frac{\eta u}{\Delta \beta} d c-(E-u) \phi_{\psi} \psi_{\gamma} d \gamma \\
0 \\
\frac{q}{p+q} d \Omega-d E
\end{array}\right)
\end{aligned}
$$

solving for the four effects of $c, \gamma, \mu$, and $\Omega$ on the number of latent entrepreneurs yields:

\section{a) Effects on latent entrepreneurs:}

$$
\frac{d u^{*}}{d c}=\frac{-\frac{\eta u}{\Delta \beta}}{-\left[\left(\mu \frac{M}{\omega}+\phi\right)-\left(\bar{\phi}_{\psi}+\psi_{\Delta}(E-u)-\mu(1-\beta) \frac{M}{\Delta \beta}\right) \frac{\left(\frac{m}{u}-\frac{m}{\omega}\right)}{(r+\phi+\mu m)} \Delta \mu \beta\right]}>0
$$




$$
\begin{aligned}
& \frac{d u^{*}}{d \mu}=\frac{\frac{M}{\beta}}{-\left[\left(\mu \frac{M}{\omega}+\phi\right)-\left(\bar{\phi}_{\psi} \psi_{\Delta}^{+}(E-u)-\mu(1-\beta) \frac{M}{\Delta \beta}\right) \frac{\left(\frac{m}{u}-\frac{m}{\omega}\right)}{(r+\phi+\mu m)} \Delta \mu \beta\right]}<0 \\
& \frac{d u^{*}}{d \gamma}=\frac{-(E-u) \phi_{\psi} \psi_{\gamma}}{-\left[\left(\mu \frac{M}{\omega}+\phi\right)-\left(\bar{\phi}_{\psi} \psi_{\Delta}^{+}(E-u)-\mu(1-\beta) \frac{M}{\Delta \beta}\right) \frac{\left(\frac{m}{u}-\frac{m}{\omega}\right)}{(r+\phi+\mu m)} \Delta \mu \beta\right]}>0 \\
& \frac{d u^{*}}{d \Omega}=\frac{\left[r+\phi+\mu \beta m+\bar{\phi}_{\psi} \psi_{\Delta}^{+}\left(\frac{E}{u}-1\right) \Delta \beta\right] \frac{u}{(r+\phi+\mu m)} \mu \frac{m}{\omega} \frac{q}{p+q}}{-\left[\left(\mu \frac{M}{\omega}+\phi\right)-\left(\bar{\phi}_{\psi} \psi_{\Delta}(E-u)-\mu(1-\beta) \frac{M}{\Delta \beta}\right) \frac{\left(\frac{m}{u}-\frac{m}{\omega}\right)}{(r+\phi+\mu m)} \Delta \mu \beta\right]}<0 \\
& \text { for } \quad 0<1-\frac{\stackrel{(-)}{\phi}}{\phi} \frac{\phi_{\psi_{i}}}{\phi_{\psi_{i} \psi_{i}}} \quad \text { as sufficient condition. }
\end{aligned}
$$

b) Effects on the rate of mobilization of entrepreneurial capacity:

$$
\begin{aligned}
& E=n+u \quad \text { for } E=1 \\
& d \Psi=d n=-d u \\
& \frac{d \Psi}{d c}=-\frac{d u}{d c}<0, \quad \frac{d \Psi}{d \gamma}=-\frac{d u}{d \gamma}<0 \\
& \frac{d \Psi}{d \mu}=-\frac{d u}{d \gamma}>0, \quad \frac{d \Psi}{d \Omega}=-\frac{d u}{d \Omega}>0
\end{aligned}
$$

c) Effects on the separation rate and the survival rate:

$$
\phi=\phi\left(\psi^{*}\left(\Delta^{*}(x), \gamma\right)\right), \quad \text { with } \quad \begin{array}{ll}
\phi_{\psi_{i}}<0, & \phi_{\psi_{i} \psi_{i}}>0 \\
\psi_{\gamma_{i}}<0, & \psi_{\Delta_{i}}>0
\end{array}
$$

From $F$ we know that $\frac{d \omega}{d u}=1$ and from $G$ we know:

$$
\begin{gathered}
0=\Delta \mu \beta \frac{m}{\omega} d \omega-\beta \Delta \mu \frac{m}{u} d u+((r+\phi+\mu m)) d \Delta \\
\frac{d \Delta}{d u}=\frac{\Delta \mu \beta}{(r+\phi+\mu m)}\left(\frac{m}{u}-\frac{m}{\omega}\right)>0
\end{gathered}
$$




$$
\begin{aligned}
& \frac{d \phi^{*}}{d c}=\frac{(-)}{\partial \phi} \frac{(+)}{\partial \psi^{*}} \frac{(+)}{\partial \psi^{*}} \frac{\stackrel{(+)}{d \Delta}}{d u} \frac{\stackrel{(+)}{d u^{*}}}{d c}<0, \quad \frac{d \lambda}{d c}=-\frac{d \phi^{*}}{d c}>0 \\
& \frac{d \phi^{*}}{d \gamma}=\frac{\partial \phi}{\partial \psi^{*}} \frac{\partial \psi^{*}}{\partial \gamma}>0, \quad \frac{d \lambda}{d \gamma}=-\frac{d \phi^{*}}{d \gamma}<0
\end{aligned}
$$

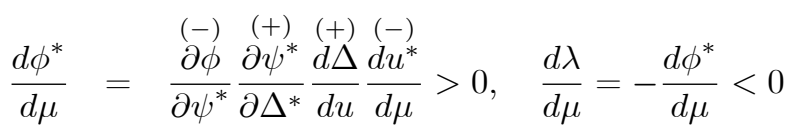

$$
\begin{aligned}
& \frac{d \phi^{*}}{d \Omega}=\frac{\stackrel{(-)}{\phi}}{\partial \psi^{*}} \frac{\partial \psi^{*}}{\partial \Delta^{*}} \frac{(+)}{d \Delta} \frac{(-)}{d u^{*}} d \Omega, \quad \frac{d \lambda}{d \Omega}=-\frac{d \phi^{*}}{d \Omega}<0
\end{aligned}
$$

d) Effects on the matching rate, as the percentage of newly started firms:

$$
\varepsilon=\frac{\mathcal{M}}{n}
$$

Under stationary conditions $(\dot{n}=0) \mathcal{M}=\phi n$ and hence $\varepsilon=\phi$. Therefore,

$$
\frac{d \varepsilon^{*}}{d c}=\frac{d \phi^{*}}{d c}<0, \quad \frac{d \varepsilon^{*}}{d \gamma}=\frac{d \phi^{*}}{d \gamma}>0, \quad \frac{d \varepsilon^{*}}{d \mu}=\frac{d \phi^{*}}{d \mu}>0
$$

